\title{
SRF CONTROL ALGORITHM BASED DVR FOR MITIGATION BALANCED AND UNBALANCED VOLTAGE DISTURBANCES
}

\author{
DR. S. VIJAYALAXMI ${ }^{1}$, I. L. B. SOWJANYA ${ }^{2}$ \& BHEEMISETTI NAGA PAVAN KUMAR \\ ${ }^{1}$ Associate Professor Usha Rama College of Engineering and Technology, Telaprolu, Krishna (Dist) Andhra Pradesh, India \\ ${ }^{2,3}$ Assistant Professor, Usha Rama College of Engineering and Technology, Telaprolu, Krishna (Dist) Andhra Pradesh, India
}

\begin{abstract}
The power quality problems occur due to voltage disturbances in the system, caused by electrical system faults, switching of large loads or energization of transformers etc. Such voltage disturbances cause short term rapid changes in amplitude of voltage. These voltage changes such as temporary voltage rise (swell) or voltage reduction (sag) are more frequent and have severe impact on the power system. Among the various custom power devices, the DVR is the most suitable one due to its low cost and simplicity in operation. In this paper, SRF (Synchronous Reference Frame Theory) based DVR (Dynamic Voltage Restorer), is considered and analysed for its performance. There are two types of voltage sag and swell which can occur on any distribution lines; balanced and unbalanced voltage sag and swell which are also known as symmetrical and asymmetrical voltage sag and swell respectively. The control strategy for extracting the compensation voltage in DVR is based on synchronous reference frame theory (SRF) along with a PI controller for generating gate pulses for the VSC. The performance of Synchronous Reference Frame (SRF) theory based DVR for the mitigation of balanced and unbalanced voltage sag, swell, sag and swell in different phase voltages is tested and simulation results carried out by MATLAB\SIMULINK are presented.

KEYWORDS: Synchronous Reference Frame Theory (SRF), Balanced and Un Balanced Voltage \& Dynamic Voltage Restorer (DVR)
\end{abstract}

Received: May 15, 2020; Accepted: Jun 05, 2020; Published: Jul 20, 2020; Paper Id.: IJMPERDJUN2020392

\section{INTRODUCTION}

The electrical power system is exposed to different types of disturbances leading to power quality problems. These problems such as voltage, current or frequency deviations may result in failure or misoperation of customer equipment. In general any deviation in voltage and frequency are considered as disturbances which effect the power quality in power distribution system. Power quality problem is any power problem manifested in voltage, current, or frequency deviation that results in failure misoperation of utility or end user equipment. The common power quality problems are short duration and long duration voltage disturbances, harmonics, electro Magnetic interference problems, transients and voltage spikes. Short duration: The disturbances in the voltage that last for duration less than one minute. Long duration: The disturbances in the voltage that last for duration more than one minute. An interruption is defined as a reduction in the supply voltage or load current to a level less than $0.1 \mathrm{p} . \mathrm{u}$. for a time not greater than 1 minute. The causes of interruption are faults in power system network, human error and improper functioning of protective equipment. Consequence of interruption leads to the stoppage of power completely for a period of time until the fault is cleared. Voltage sag is defined as a decrease in root mean square (RMS) voltage or current at the power frequency for duration from 0.5 cycles to 1 minute. Swell is defined as an increase in RMS voltage between 1.1 to 1.8 p.u. at the power frequency for a duration between 0.5 cycles to one minute. SLG fault 
can result in voltage swell in the unfaulted phases. The fundamental frequency of the AC electric power distribution system is $50 \mathrm{~Hz}$. Harmonic frequencies are any sinusoidal frequencies, which are multiples of the fundamental frequency. The harmonic frequencies can be even or odd multiples of the sinusoidal fundamental frequency. Inter-harmonics are sinusoids whose frequencies are non integer multiples of fundamental frequency. Sub-harmonics are sinusoids whose frequencies are fractional multiples of the fundamental frequency. Electro Magnetic Interference (EMI) is also known as radio frequency interference when in the radio frequency spectrum if a disturbance is generated by an external source it may affect an electrical circuit by electromagnetic induction or electrostatic coupling or conduction. Ninety-five percent of all EMI problems tend to be Electric Field (E-Field) related. These are temporary, undesirable voltages that appear on the power supply line. These are high over-voltage disturbances (up to 20KV) that last for a very short time. These are undesirable but decay with time and hence not a steady state problem. Transients are present in the system for a very short duration up to few cycles of the input voltage. This will lead to increase or decrease in magnitude of voltage or current. Transients are classified into two types namely first one is impulsive and second one is oscillatory. Impulsive transients occur due to lightning or any other faults. Oscillatory transients are occur due to switching ON/OFF operation. In balanced voltage sag \&swell, voltage decreases and increase in all three phases simultaneously respectively. In unbalanced voltage sag \&swell voltage decrease and increases in only one phase or two and three phases at a time [2,3,4].

\section{MATHEMATICAL MODEL OF DVR}

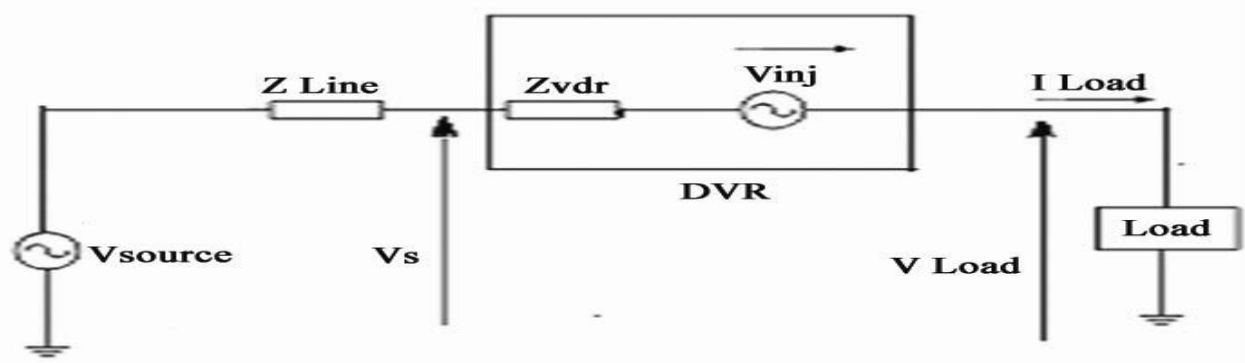

Figure 1: DVR-Equivalent Circuit.

DVR injects required mitigation voltage in boost mode of operation $\left(V_{D V R}>0\right)$, through booster transformer when it detects during source voltage disturbance. Figure 4.1 shows the DVR equivalent circuit. As soon as the voltage source goes down or rises DVR adds or subtracts a series voltage $V_{i n j}$ through the injection transformer given by equation (1) and (2). By this means load voltage magnitude $V_{\text {Load }}$ is retained. The injected or absorbed series voltage of the DVR can be written as,

$$
\begin{aligned}
& V_{\text {inject }}=V_{\text {Load }}-V_{S} \\
& V_{\text {Absorb }}=V_{S}-V_{\text {Load }}
\end{aligned}
$$

Where,

$\mathrm{V}_{\text {Loadis }}$ the magnitude of the load voltage

$\mathrm{V}_{\mathrm{S}}$ is the source voltage under sag / swell condition. The load currenI $\mathrm{L}_{\text {Load }}$ is given by

$$
I_{\text {Load }}=\left[\frac{P_{\text {Load }-*^{*} Q_{\text {Load }}}}{V_{\text {Load }}}\right]
$$




\section{DVR WITH SRF CONTROL ALGORITHM}

The major role of this control method is to maintain constant voltage magnitude at the sensitive load point, under the supply disturbances. The proportional response can be adjusted by multiplying the error by proportional gain DE. The contribution from integral term is proportional to both error duration and the error

magnitude. The proportional plus integral controller is called as PI controller. It has two gain constants which includes the proportional gain kp and integral gain ki. Figure 2 shows the DVR Block Diagram and figure.3 shows the Control Block Diagram of the DVR with SRF theory. The source voltage Vsabc is sensed and given as an input to the transformation block (abc/dq) and the same source voltage (Vsabc) is also given as an input to the PLL block. The PLL block generates sin and cos functions. These are given as inputs to the inverse transformation block (dq/abc). The input transformation block results in $\mathrm{Vd}, \mathrm{Vq}$, and Vo and these are compared with Vdact, Vqact and Voact which are the actual parameters and the error generated is given as an input to the PI controller. The PI controller output is again given as an input to dq/abc block, and PLL information is also given as an input to this block. This block gives the pulse information which is given as an input to PWM generator and from that gate pulses are generated for inverter.

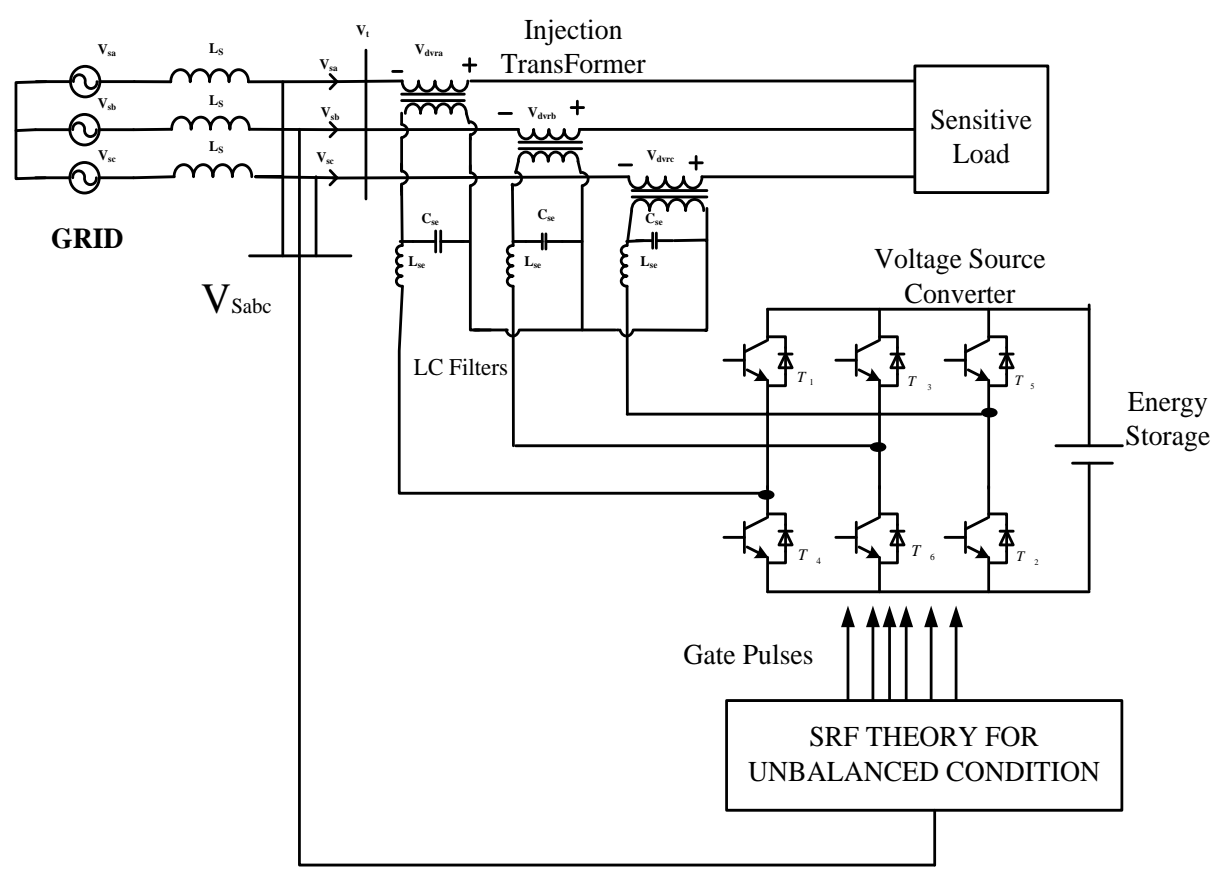

Figure 2: DVR Block Diagram With SRF. 


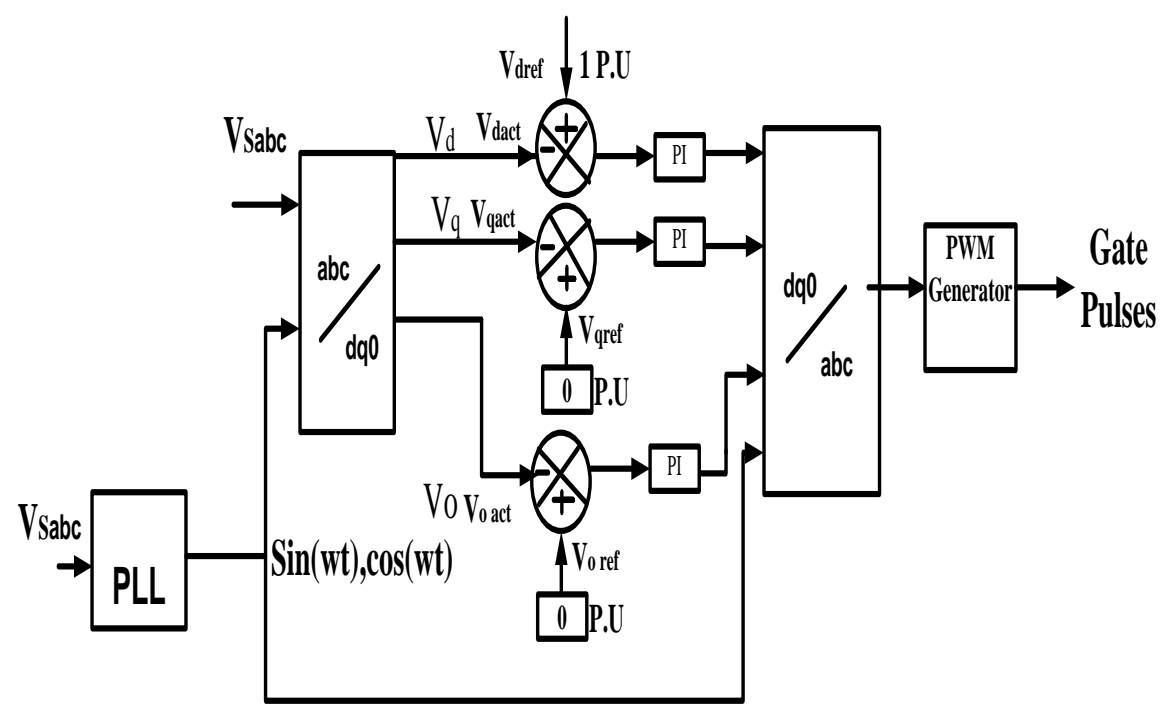

Figure 3: DVR Control Block Diagram Based on SRF Theory.

\section{MATLAB / SIMULATION RESULTS AND DISCUSSIONS}

Table 1: System Parameters for Simulation

\begin{tabular}{|c|l|c|}
\hline S. No & \multicolumn{1}{|c|}{ Parameters } & Designed Values \\
\hline 1 & Supply voltage $\left(\mathrm{V}_{\mathrm{S}}\right)$ & $440 \mathrm{~V}$ \\
\hline 2 & Supply frequency $(\mathrm{F})$ & $50 \mathrm{~Hz}$ \\
\hline 3 & Source Resistance $(\mathrm{R})$ & $0.1 \Omega$ \\
\hline 4 & Source Inductance $(\mathrm{L})$ & $2.5 \mathrm{NH}$ \\
\hline 5 & Load power $\left(\mathrm{P}_{\mathrm{L}}\right)$ & $10 \mathrm{KW}$ \\
\hline 6 & Proportional Gain $\left(\mathrm{K}_{\mathrm{p}}\right)$ & 10 \\
\hline 7 & Integral Gain $\left(\mathrm{K}_{\mathrm{i}}\right)$ & 1 \\
\hline 8 & DCvoltage $(\mathrm{V})$ & 550 \\
\hline 9 & Injection Transformer Turns Ratio & $1: 1$ \\
\hline
\end{tabular}

The DVR is modelled and simulated using the sim power system tool box. The three-phase programmable source is connected to the three-phase load through the DVR in order to mitigate identified voltage quality problem like balanced and unbalanced sag/swell at supply side. PI controller is used for the control operation of the DVR. The proportion and integral gains of PI controller are tuned by trial and error method. The DVR system is connected in series to the power distribution line through injection transformer to inject voltage at PCC and the obtained load voltage is nearly constant. The simulation is carried out using MATLAB/SIMULINK software and simulation diagrams are presented in fig..4\&10. Results are shown for balanced and unbalanced voltage sag and swell in three phases of power distribution line in figures 5 to 13 . It is seen that DVR based SRF control algorithm effectively mitigates the various voltage disturbances like sag, swell and sag/swell. 


\section{CASE 1: Mitigation of Balanced Sag in Three Phases of the System}

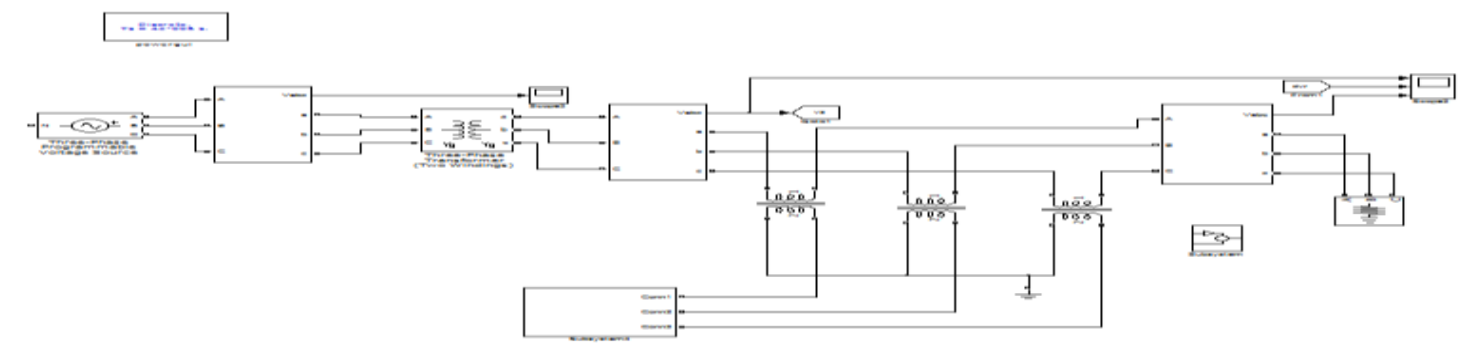

Figure 4: Simulation Diagram for Mitigation of Balanced Voltage

Sag and Swell using SRF Control Algorithm based DVR.

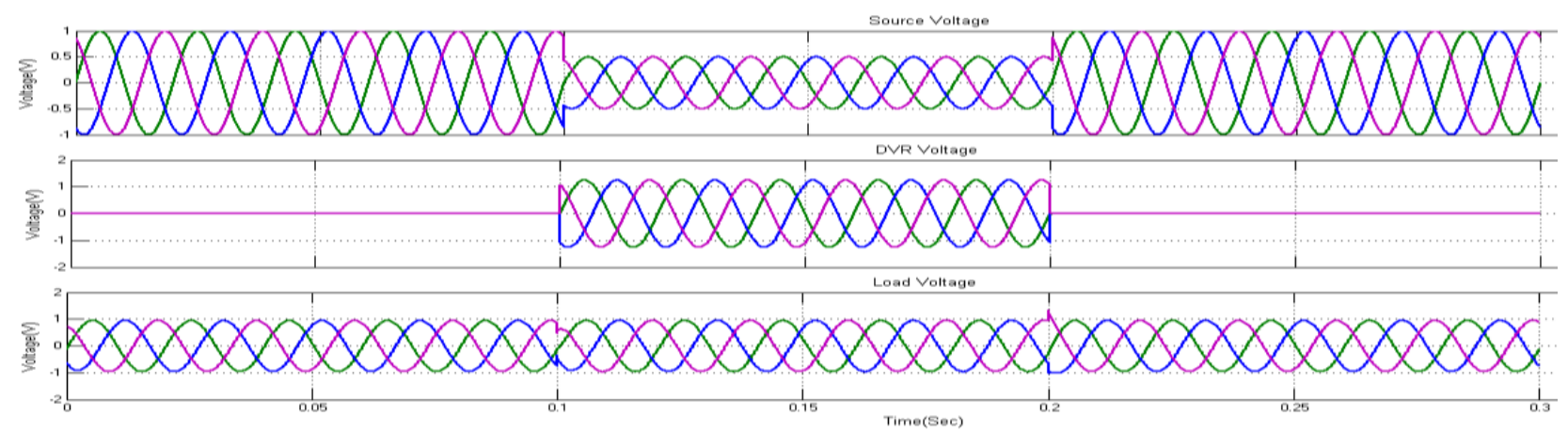

Figure 5: Results for Three Phases Sag Condition.

(a)Source Voltage (b) DVR Voltage (c) Load Voltage.

The Matlab/simulation results of the SRF control algorithm based DVR with PI controller for balanced voltage sag condition of depth $0.45 \mathrm{pu}$ in three phases occurring for a duration from $0.1 \mathrm{sec}$ to $0.2 \mathrm{sec}$ due to (LLL-G) fault in the system is given in figure.5 (a) shows the RMS voltage waveform of the source voltage of the system. Figure (b) indicates the injected voltage by DVR which is nothing but the mitigation voltage. The third waveform (c) denotes the voltage present across sensitive load which is equal to source voltage plus voltage injected by DVR. It is seen that the DVR nearly mitigates the load voltage.

CASE 2: Mitigation of Balanced Swell in Three Phases of the System

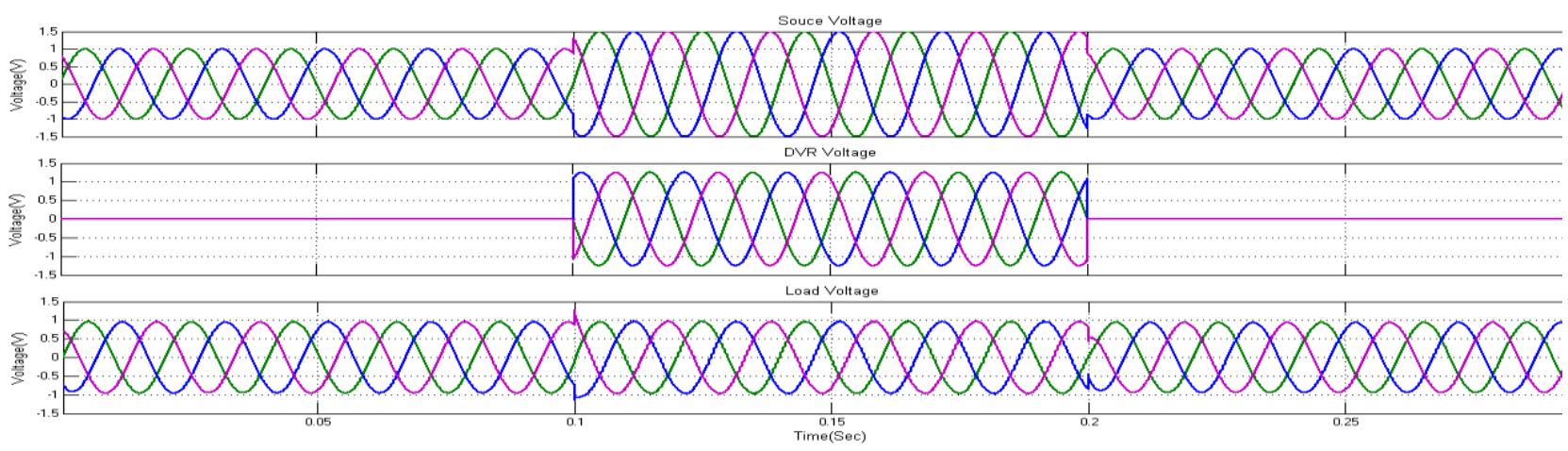

Figure 6: Results for Three Phases Swell Condition.

(a) Source Voltage (b) DVR Voltage (c) Load Voltage

The Matlab/simulation results of the SF control algorithm based DVR with PI controller for balanced voltage swell condition of depth $1.42 \mathrm{pu}$ in three phases occurring for a duration from $0.1 \mathrm{sec}$ to $0.2 \mathrm{sec}$ and due to switching ON large 
capacitor banks in the system is given in figure 6. (a) shows the RMS voltage waveform of the source voltage of the system. Figure (b) indicates the absorbed voltage by DVR which is nothing but the mitigation voltage. The third waveform (c) denotes the voltage present across sensitive load which is equal to source voltage plus voltage injected by DVR. It is seen that the DVR nearly mitigates the load voltage.

CASE 3: Mitigation of Multiple Balanced Sag in Three Phases of the System

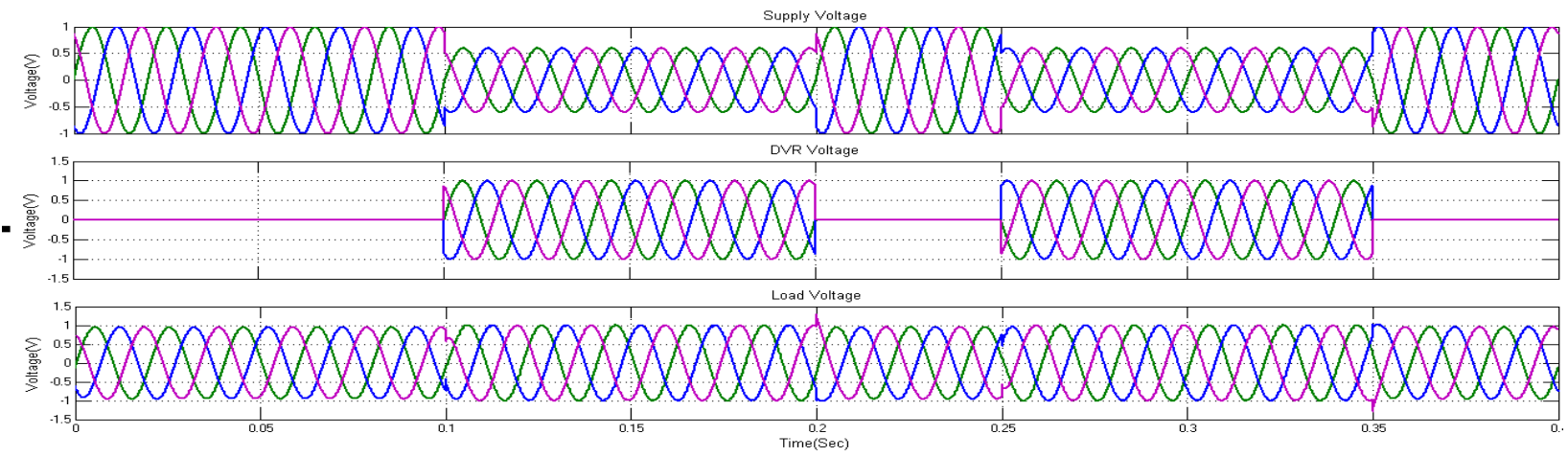

Figure 7: Results for Three Phases Sag Condition (a) Source Voltage (b) DVR Voltage (c) Load Voltage.

The Matlab/simulation results of the SRF control algorithm based DVR with PI controller for multiple balanced voltage sag condition of depth $0.45 \mathrm{pu}$ in three phases occurring for a duration from $0.1 \mathrm{sec}$ to $0.2 \mathrm{sec}$ and 0.25 to $0.35 \mathrm{sec}$ due to (LLL-G) fault in the system is given in figure 7 (a) shows the RMS voltage waveform of the source voltage of the system. Figure (b) indicates the injected voltage by DVR which is nothing but the mitigation voltage. The third waveform (c) denotes the voltage present across sensitive load which is equal to source voltage plus voltage injected by DVR. It is seen that the DVR nearly mitigates the load voltage.

CASE 4: Mitigation of Multiple Balanced Swell in Three Phases of the System

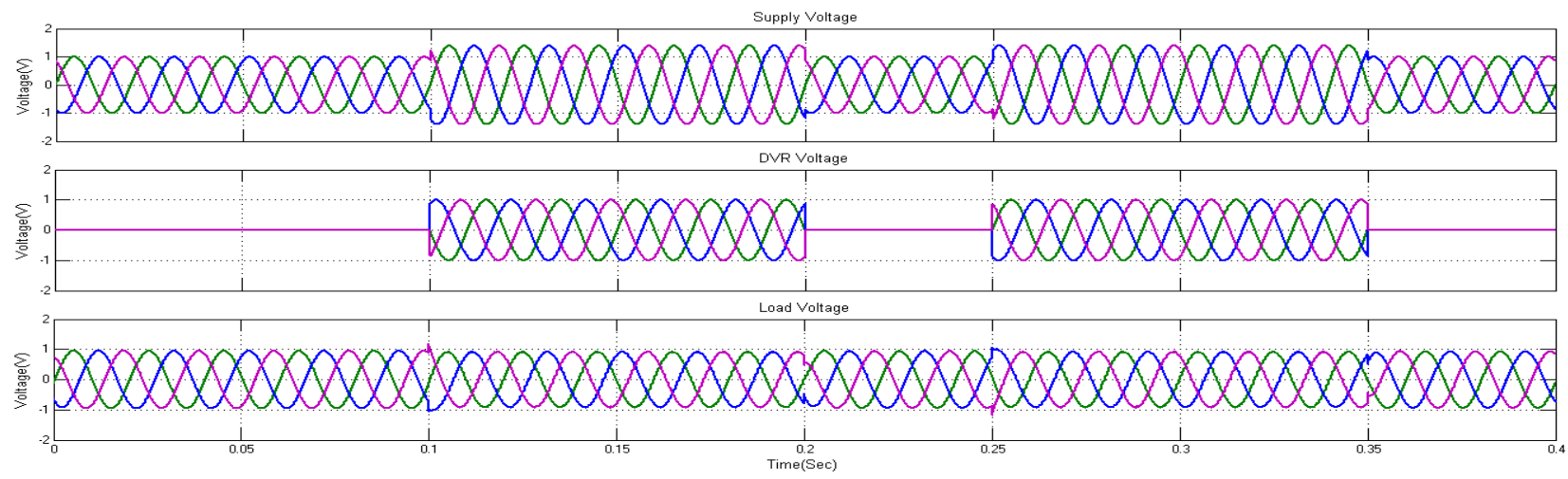

Figure 8: Results for Three Phases Swell Condition.

(a) Source Voltage (b) DVR Voltage (c) Load Voltage

The Matlab/simulation results of the SF control algorithm based DVR with PI controller for balanced voltage swell condition of depth $1.42 \mathrm{pu}$ in three phases occurring for a duration from $0.1 \mathrm{sec}$ to $0.2 \mathrm{sec}$ and 0.25 to $0.35 \mathrm{sec}$ due to switching ON large capacitor banks in the system is given in figure 8. (a) shows the RMS voltage waveform of the source voltage of the system. Figure (b) indicates the absorbed voltage by DVR which is nothing but the mitigation voltage. The third waveform (c) denotes the voltage present across sensitive load which is equal to source voltage plus voltage injected by DVR. It is seen that the DVR nearly mitigates the load voltage. 
CASE 5: Mitigation of Balanced Sag and Swell in Three Phases of the System

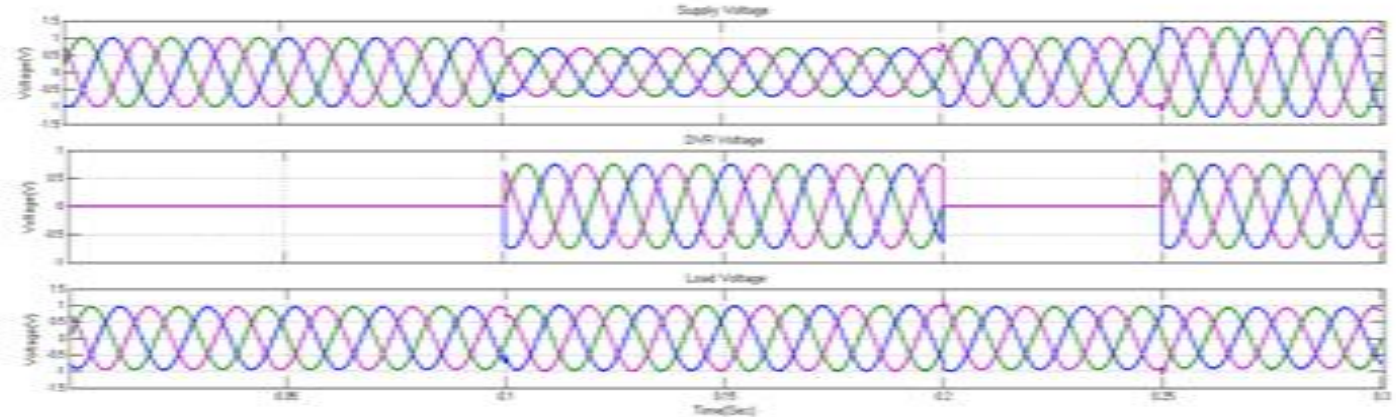

Figure 9: Results for Three Phases Sag and Swell Condition.

(a) Source Voltage (b) DVR Voltage (c) Load Voltage

The Matlab/simulation results of the SRF control algorithm based DVR with PI controller for voltage sag and swell condition of depth 0.68 and $1.13 \mathrm{pu}$ in three phases occurring in different durations from $0.1 \mathrm{sec}$ to $0.2 \mathrm{sec}$ and $0.25 \mathrm{sec}$ to $0.3 \mathrm{sec}$ due to (LLL-G) fault and switching on large capacitor banks in the system respectively is given in figure 9. (a) shows the RMS voltage waveform of the source voltage of the system. Figure (b) indicates the injected/ absorbed voltage by DVR which is nothing but the mitigation voltage. The third wave form (c) denotes the voltage present across sensitive load which is equal to source voltage plus voltage injected by DVR. It is seen that the DVR nearly mitigates the load voltage.

\section{CASE 6: Mitigation of Multiple Unbalanced Sag in Three Phases of the System}

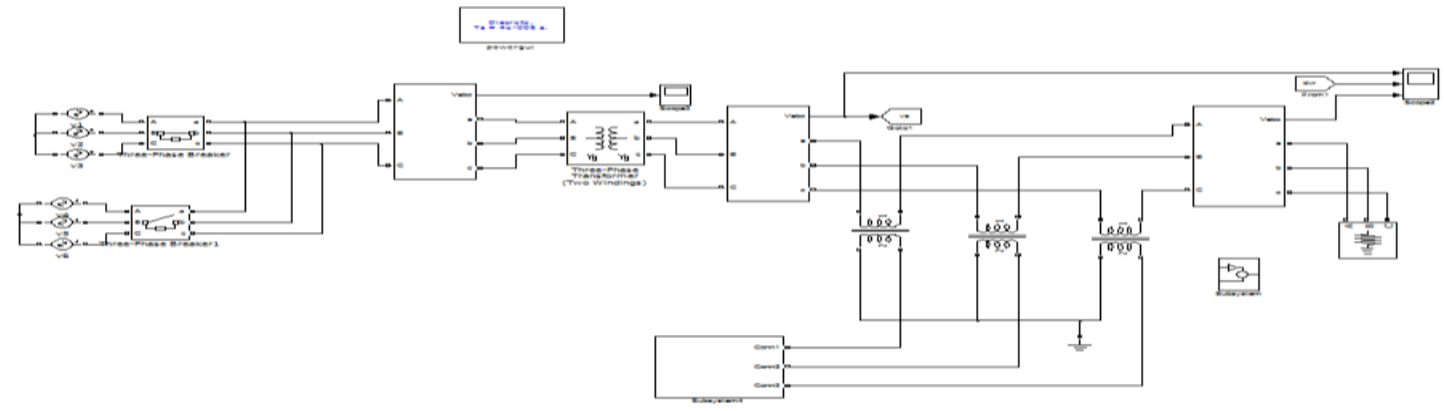

Figure 10: Simulation Diagram for Mitigation of Unbalanced Voltage Sag and Swell using SRF Control Algorithm Based DVR.

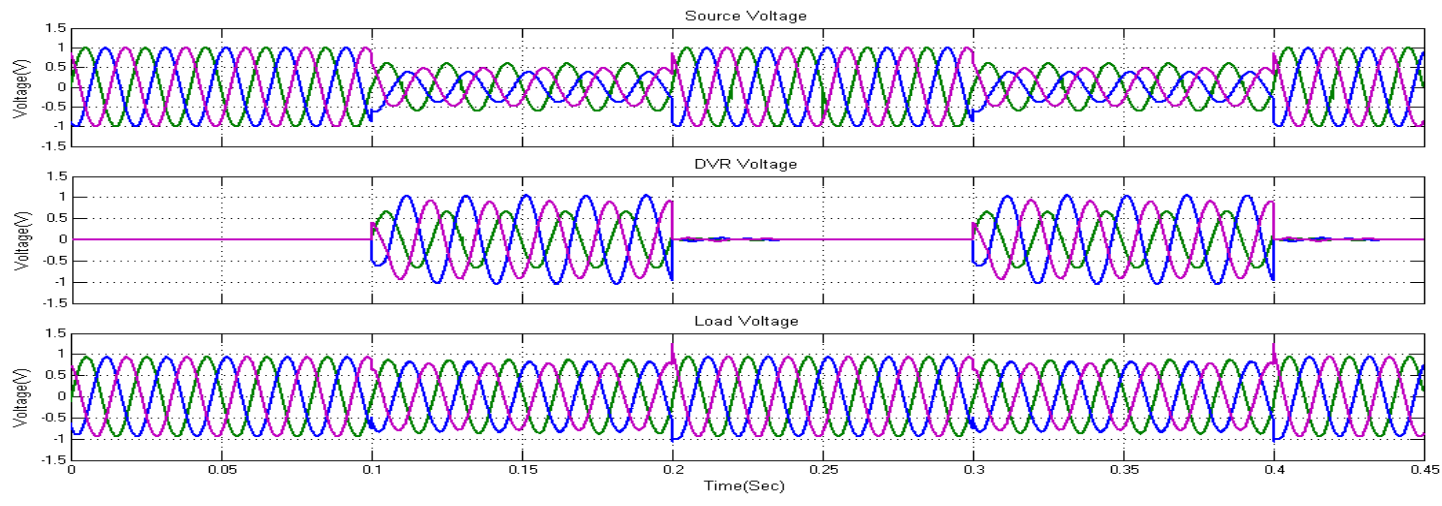

Figure 11: Results for Three Phases Sag Condition (a) Source Voltage (b) DVR Voltage (c) Load Voltage 
The Matlab/simulation results of the SRF control algorithm based DVR with PI controller for multiple unbalanced voltage sag condition of depth $0.45 \mathrm{pu}$ in three phases occurring for a duration from $0.1 \mathrm{sec}$ to $0.2 \mathrm{sec}$ and 0.3 to $0.4 \mathrm{sec}$ due to (LLL-G) fault in the system is given in figure 11 (a) shows the RMS voltage waveform of the source voltage of the system. Figure (b) indicates the injected voltage by DVR which is nothing but the mitigation voltage. The third waveform (c) denotes the voltage present across sensitive load which is equal to source voltage plus voltage injected by DVR. It is seen that the DVR nearly mitigates the load voltage.

CASE 7: Mitigation of Multiple Unbalanced Swell in Three Phases of the System

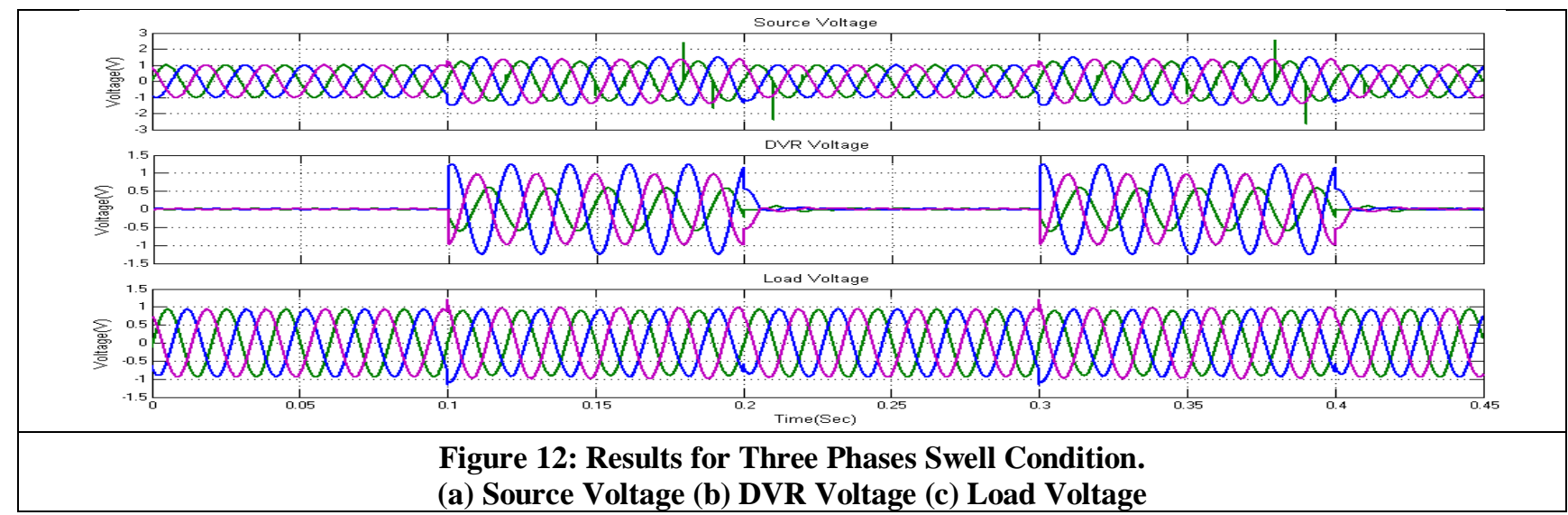

The Matlab/simulation results of the SF control algorithm based DVR with PI controller for unbalanced voltage swell condition of depth $1.42 \mathrm{pu}$ in three phases occurring for a duration from $0.1 \mathrm{sec}$ to $0.2 \mathrm{sec}$ and 0.3 to $0.4 \mathrm{sec}$ due to switching ON large capacitor banks in the system is given in figure 12. (a) shows the RMS voltage waveform of the source voltage of the system. Figure (b) indicates the absorbed voltage by DVR which is nothing but the mitigation voltage. The third waveform (c) denotes the voltage present across sensitive load which is equal to source voltage plus voltage injected by DVR. It is seen that the DVR nearly mitigates the load voltage.

\section{CASE 8: Mitigation of Unbalanced Sag and Swell in Three Phases of the System}

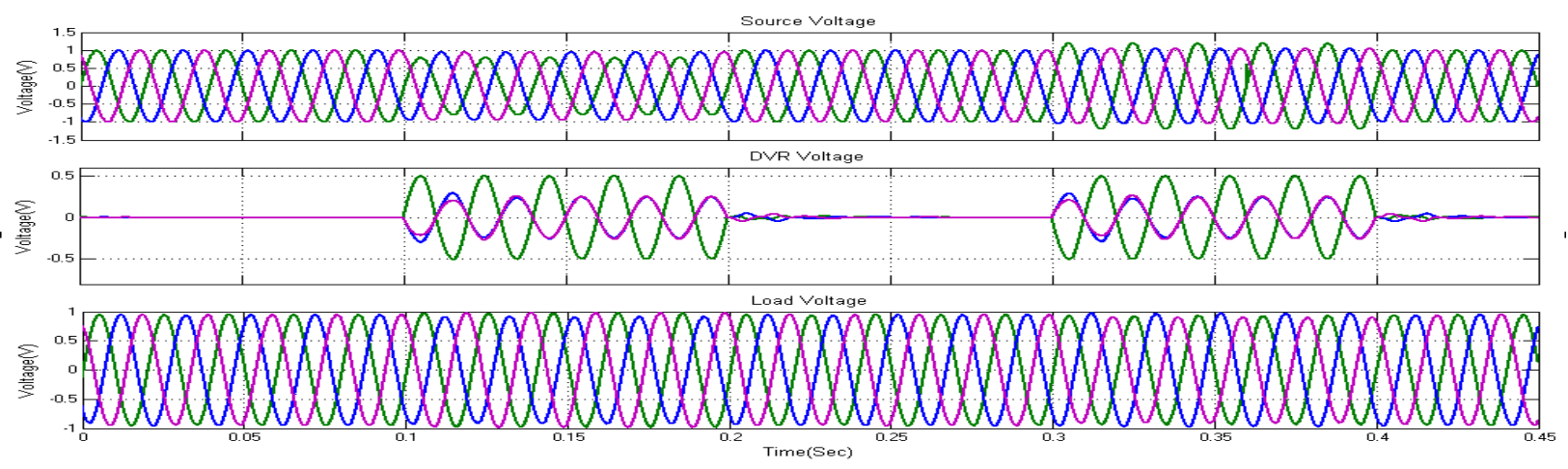

Figure 13: Results for Three Phases Sag and Swell Condition (a) Source Voltage (b) DVR Voltage (c) Load Voltage

The Matlab/simulation results of the SRF control algorithm based DVR with PI controller for unbalanced voltage sag and swell condition of depth 0.68 and 1.13 pu in three phases occurring in different durations from $0.1 \mathrm{sec}$ to $0.2 \mathrm{sec}$ and $0.3 \mathrm{sec}$ to $0.4 \mathrm{sec}$ due to (LLL-G) fault and switching ON large capacitor banks in the system respectively is given in figure 
13. (a) shows the RMS voltage waveform of the source voltage of the system. Figure (b) indicates the injected/ absorbed voltage by DVR which is nothing but the mitigation voltage. The third waveform (c) denotes the voltage present across sensitive load which is equal to source voltage plus voltage injected by DVR. It is seen that the DVR nearly mitigates the load voltage.

\section{CONCLUSIONS}

In this paper, SRF (Synchronous Reference Frame Theory) control algorithm based DVR (Dynamic Voltage Restorer), is considered and analysed for its performance. The gains of PI controller (DE 0 10) and (D\% 0 1) are tuned by trial and error method. The simulation is carried out using MATLAB/SIMULINK software and simulation diagrams are presented in figure $4 \& 10$. Results are shown for balanced and unbalanced voltage sag and swell in three phases of typical power distribution system in figures .5. to 13. It is seen that DVR based SRF control algorithm effectively mitigates the various voltage disturbances like multiple balanced and unbalanced sag, swell and sag/swell.

\section{REFERENCES}

1. Bollen MHJ. Understanding power quality problems. Piscataway, NJ: IEEE Press; 2006.

2. Lim PK, Dor DS. Understanding and resolving voltage sag related problems for sensitive industrial customers. IEEE Power Eng Soc Winter Meet 2000; 4:2886-90.

3. S. Leela, S. Dash "Control of three level inverter based DVR"

4. Reddy, V. K., et al. "Performance analysis of DSTATCOM compensator using control techniques for load compensation." Int. J. Electr. Electron. Eng. Res. 1.2 (2011): 149-171.

5. Rating and Design Issues of DVR Injection Transformer

6. Performance of DVR under different voltage sag and swell conditions by T. Devaraju, V. C. Reddy and M. Vijaya Kumar

7. Voltage Quality Improvement Using DVR by Chellali Benachaiba, Brahim ferdi

8. Chellali Benachaiba, Bra-him Ferdi “Voltage Quality Improvement Using DVR"

9. Laxmi, S. Vijaya, and PV Ramana Rao. "Super Conducting Magnetic Energy System with Dvr for Voltage Quality Improvement Using Pso Based Simple Abc Frame Theory."International Journal of Electrical and Electronics Engineering Research (IJEEER) 7. 2, Apr 2017, 1-10

10. Bhim Singh, P. Jayaprakash, and D. P. Kothari "Adeline-Based Control of Capacitor Supported DVR for Distribution System”

11. A. K. Sadigh and K. M. Smedley, “Review of voltage compensation methods in dynamic voltage restorer (DVR)," in Proc. IEEE Power Energy Soc. Gen. Meet., Jul. 2012, pp. 1-8

12. Venkateswarlu, G., M. Pavan, and P. Raju. "Improvement Of The Voltage Stability In The Distribution System By Using The Multifunctional Dynamic Voltage Restorer." International Journal of Electrical and Electronics Engineering (IJEEE) 3.1 (2014): 37-48.

13. Dr. T. Ruben; Deva Prakash; G.Justin; Sunil Dhas; “A Novel approach for Voltage Sag Mitigation Using FACTS Device Interline Dynamic Voltage Restorer"978-1-4244-8679- 3/11/\$26.00@2011IEEE”"

14. A. Y. Goharrizi, S. H. Hosseini, M. Sabahi, and G. B. Gharehpetian, "Three-phase HFL-DVR with independently controlled phases," IEEE Trans. Power Electron., vol. 27, no. 4, pp. 1706-1718, Apr. 2012. 
15. E. Babaei M. FarhadiKangarlu, —Voltage quality improvement by a dynamic voltage restorer based on a direct three-phase converter with fictitious DC linkl, IET Gener. Transm. Distrib., 2011, Vol. 5, Iss. 8, pp. 814-823.

16. Eashwaramma, N., J. Praveen, and M. Vijayakumar. "Modelling and Designing of Cascaded 9 Level Voltage Source Converter Based on DVR for Mitigating Harmonics in Distributed Power System Using Unit Vector." International Journal of Electrical and Electronics Engineering Research (IJEEER) 8.1 (2018): 11-20.

17. P. Kanjiya, B. Singh, A. Chandra, and K. Al-Haddad, "SRF theory revisited to control self-supported dynamic voltage restorer (DVR) for unbalanced and nonlinear loads, " IEEE Trans. Ind. Appl., vol. 49, no. 5, pp. 2330-2340, Sep./Oct. 2013.Rating and Design Issues of DVR Injection Transformer. 